\title{
The Evolution of Dental Materials for Hybrid Prosthesis
}

\author{
Jorge Gonzalez
}

\author{
3302 Gaston Ave, Dallas TX, 75246, Center for Maxillofacial Prosthetic Clinic, Baylor College of Dentistry, \\ Room \#169, USA
}

\begin{abstract}
Since the immemorial, the replacement of missing teeth has been a medical and cosmetic necessity for human kind. Nowadays, middle-aged population groups have experienced improved oral health, as compared to previous generations, and the percentage of edentulous adults can be expected to further decline. However, with the continued increase in the number of older adult population, it is anticipated that the need for some form of full-mouth restoration might increase from 53.8 million in 1991 to 61 million in 2020 [1]. Denture prosthetics has undergone many development stages since the first dentures were fabricated. The introduction of computer-aided design/computer aided manufacturing (CAD/CAM) has resulted in a more accurate manufacturing of prosthetic frameworks, greater accuracy of dental restorations, and in particular, implant supported prosthesis.
\end{abstract}

Keywords: Cantilevers, complete edentulous, computer-assisted design/computer-assisted machining (CAD/CAM), dental implants, hybrid prosthesis, intraoral scanner, zirconia.

\section{HISTORIC PERSPECTIVES}

Since the immemorial, the replacement of missing teeth has been a medical and cosmetic necessity for human kind. Denture prosthetics has undergone many development stages since the first still preserved dentures were fabricated. While 3,500 years ago, the ancient Egyptians carved false teeth out of mulberry wood and tied them to the adjacent teeth with gold wire, the Etruscans arrived at considerable skill, producing construction made of gold and bovine teeth, which were already guided by principles used in denture prosthetics today [2].

Dental technology remained virtually undeveloped until the $18^{\text {th }}$ century. Candidate materials for artificial teeth during the $18^{\text {th }}$ century were (1) human teeth, (2) animal teeth carved to the size and shape of human teeth, (3) ivory, and finally (4) "mineral" or porcelain teeth. Other than for costly human teeth that were scarce, the selection of artificial tooth materials was based on their mechanical versatility and biologic stability. Animal teeth were unstable toward the "corrosive agents" in saliva, and elephant ivory and bone contained pores that easily stained. Hippopotamus ivory appears to have been more desirable than other esthetic dental substitutes [3, 4], John Greenwood carved teeth from hippopotamus ivory for at least one of the four sets of complete dentures he fabricated for George Washington [5]. Lower dentures, made of ivory with inset of cadaver teeth, worked reasonable well and managed to stay in place without too much difficulty, especially if weighted with some lead. The difficulties really came to the fore with the upper denture,

*Address correspondence to this author at the 3302 Gaston Ave, Dallas TX, 75246, Center for Maxillofacial Prosthetic Clinic, Baylor College of Dentistry, Room \#169; Tel: 214-828-8990; E-mail: jgonzalez@ bcd.tamhsc.edu which refused to stay in place due to both the heavy weight and the poor fit. In order to overcome this problem, upper dentures were fashioned onto the lower dentures by means of springs or hinges. This technique would ensure that the upper denture would always be pushed up against the roof of the mouth [6].

The first porcelain teeth were developed as early as in 1709 after the introduction of porcelain manufacturing secrets by Father d'Entrecolle, a Jesuit priest who had spent many years in China, but their massive production was not undertaken until 1837 [2]. This end the practice of transplanting freshly extracted human teeth and supplanted the use of animal products [5].

In 1774, Alexis Duchateau and Nicholas Dubois de Chemant, made the first successful porcelain dentures at the Guerhard porcelain factory [5,7].

A new era was marked for dental prosthetics after Charles Goodyear in 1850 invented the vulcanization process. In this process, rubber was hardened in the presence of sulphur to produce a material call vulcanite, this material was not only cheap but was also easy to work with; it could be molded to provide an accurate fit of the denture base to the model and hence to the oral structures. The first sets of dentures based on rubber and porcelain began to appear in 1881 when the patent expired in and less expensive dentures could be made available to the masses of people in need of them [6].

In 1930's Dr. Walter Bauer introduced polymethyl methacrylate (PMMA), an amorphous polymer, highly transparent and rather brittle, yet highly stable towards aqueous media and UV radiation, tasteless, easy to repair and high shape stability [8], a suitable candidate for vulcanite substitute. 


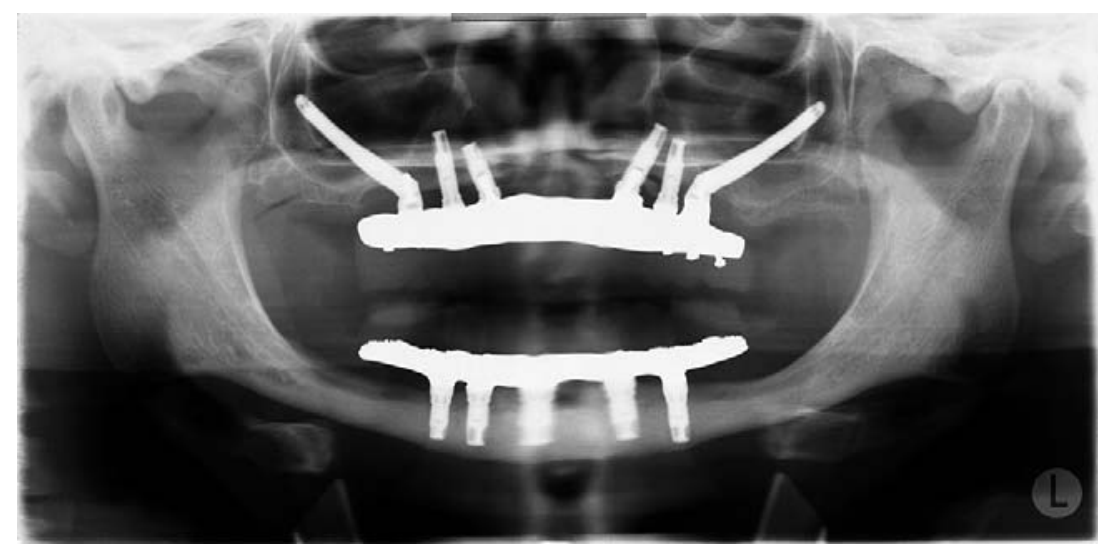

Fig. (1). Conventional design for hybrid prosthesis with long distal cantilevers.

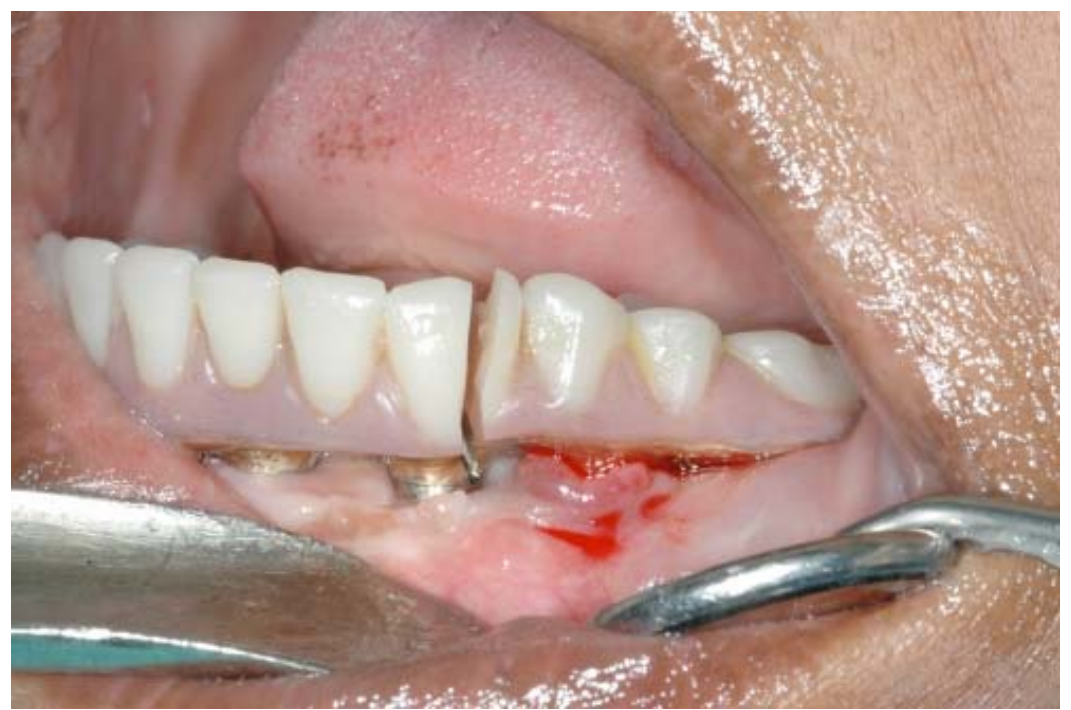

Fig. (2). Catastrophic fracture of distal extension due to extensive cantilever.

\section{HISTORY OF IMPLANTS}

The history of dental implants is as fascinating as it is ancient [9-12]. There do not appear to have been any geographical restraints to the desire of early dental practitioners to provide replacements for missing or diseased teeth. Dental implants and transplant history can be traced to Africa (Egyptians), to the Americas (Mayans, Aztecs and Incas), and to the Middle East. Also in this earliest historical period, tooth transplants can be traced to the Greeks, the Etruscan, and the Romans [13]. The first endosseous implant that present oseointegration is probably from the Mayans $\left(7^{\text {th }}\right.$ century AD) where sea shells were carved as tooth shape and placed in the mandible [14].

Today dental implants have become one of the most exciting and rapidly developing aspects of dental practice. The rapid increase in the acceptability of dental implants as regular treatment in the late $20^{\text {th }}$ and early $21^{\text {st }}$ centuries is largely attributable to Swedish Professor Per-Ingvar Brånemark during the 1950's, an orthopedic surgeon who turned an accidental discovery into a dental revolution [15] a new form of attachment mechanism; the osseointegration. Osseointegration is a biological concept and refers to the incorporation within living bone of an inanimate (metal) component. Most implants are made out of titanium and placed into the bone of the jaws by surgical means, and protrude through the mucosal tissues to provide attachment anchorage of replacement artificial teeth [16].

\section{HYBRID PROSTHESIS}

The fixed-removable prosthesis resembles a flangeless denture that is retained solely by several osseointegrated implants. There is no contact between the prosthesis and the tissues of the alveolar ridge.

The original design of the fixed-removable prosthesis was developed by Swedish investigators using the two-stage endosseous implant system developed by Brånemark. The prosthesis consisted of a gold alloy framework attached to the copings of the implant. Acrylic resin denture teeth were arranged on the framework and secured with acrylic resin [17]. The fixed-removable prosthesis represented a unique aspect of prosthodontics reconstruction for edentulous arches, since implants were situated in the anterior region and the posterior sections of the framework were cantilevered from the anterior portion of the framework (Fig. 1). The length, height, and width of the cantilever are crucial in minimizing the amount of deformation of the prosthesis (Fig. 2). According to Glantz, the mount of deformation of the cantilever is directly proportional to the cube of the 


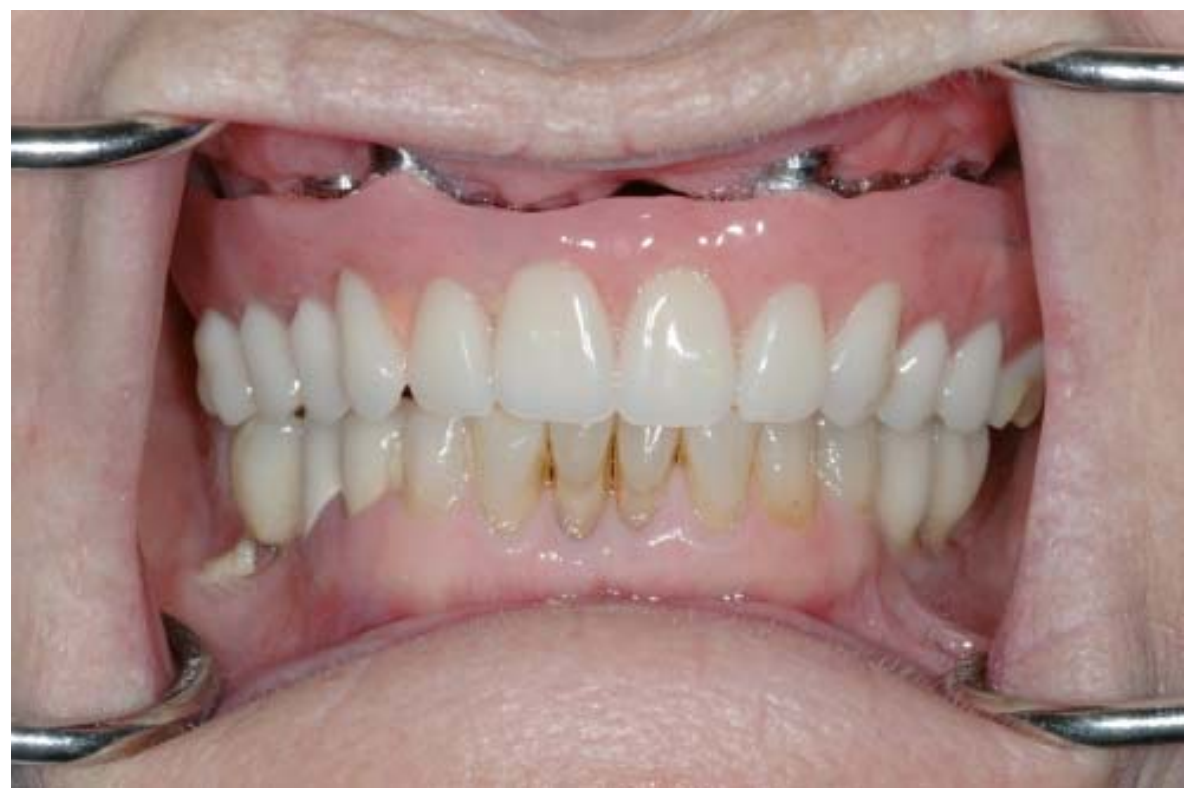

Fig. (3). Excellent maintenance and oral hygiene after 3 years from maxillary hybrid prosthesis delivery.

length and inversely proportional of the width and the cube of the height of the cantilever [18]. In addition, there is a direct relation between the amount of deformation and the force of the occlusion (loading force) as well as an inverse relation with the modulus of elasticity of the material to be used for the framework. This relationship can be expressed in the following equation:

\section{$\mathrm{D}=\mathrm{F} \times \mathrm{L} \times$ constant $/ \mathrm{E} \times \mathrm{W} \times \mathrm{H}$}

Where $\mathrm{D}$ is the amount of deformation, $\mathrm{F}$ is the force of occlusion, $\mathrm{L}, \mathrm{W}$, and $\mathrm{H}$ are the length, width, and height of the cantilever, respectively, and $\mathrm{E}$ is the modulus of elasticity of the material. Therefore, the length of the cantilever should be minimized while maximizing the height and width of the cantilever. It has been recommended that the cantilever should not exceed $20 \mathrm{~mm}$ in length using five or more abutments. If four abutments are used the cantilever should not exceed $15 \mathrm{~mm}$ in length [19]. Other studies have shown that the length of the extension should be shorter in the maxillary arch as opposed to the mandibular arch because there is less cortical bone present in the maxilla [20]. The junction of the cantilever and the distal abutments should be provided with added height and width as this area is the primary stress point in relation to the cantilever. There should be about 1 to $2 \mathrm{~mm}$ of space between the inferior border of the cantilever and the alveolar ridge to allow for adequate oral hygiene. It is recommended that the metal alloy possess sufficient yield strength $(>300 \mathrm{MPa})$ and modulus of elasticity $(>80,000$ $\mathrm{MPa})$ to prevent deformation and fracturing of the cantilevers. The literature reports casting the framework in type IV gold or precious metal alloys such as silver-palladium alloy [21]. The use of posterior prosthetic teeth with minimal inclinations is recommended to minimize and lateral forces on the cantilevers during excursive movements. Acrylic resin prosthetic teeth should be used to absorb the shock of occlusal forces [16].

Brånemark has stated that "critical to the maintenance of osseointegration the carefully controlled and prosthetic- induced loading of the implant-tissue interface". He stressed that a controlled mechanical environment is necessary to assure adequate remodeling stimulus for maintenance of integration [22, 23]. Osseointegrated implants supporting fixed prostheses are exposed to both dynamic and static loading. Dynamic forces on the implants may arise due to chewing and can reach various magnitudes [24]. Static loading on the other hand may be induced by the tension in the bridge locking screws, when securing a misfitting framework to the implants [25]. To help clinicians understand the importance of controlled loading, he stated the precision of the prosthesis fit should be at the $10 \mu \mathrm{m}$ level.

According to Zarb and Jansson, frameworks in fixed prostheses could be designed in one of the two ways: (1) where metal frameworks comprised the bulk of the prostheses, and artificial teeth and minimal denture bases were the only non-metallic components. (2) Implant fixed prostheses consisting mostly of acrylic resin denture bases (wraparound design) and artificial teeth, with minimally sized metal frameworks [17].

Esthetic demands tend to be more dramatic with maxillary prostheses than mandibular prostheses (Fig. 3). As per Zarb and Schmitt, unlike mandibular implant prostheses were hygienic type designs have proven to be functionally and esthetically acceptable, maxillary implant prostheses demand different sized and shaped labial/buccal flanges that may or may not compensate for optimal esthetics, phonetics, and masticatory function (Fig. 4). Additionally prosthetic gingival tissues are often required due to resorptive patterns of edentulous maxillae. Resorptive patterns in maxillae are dissimilar to mandibular resorption pattern: maxillae resorb superiorly, posteriorly, and medially: mandible resorbs inferiorly, anteriorly, and laterally [26, 27].

\section{ALL ON 4}

Implant treatment was based on basic prosthodontics principles that included preliminary and definitive impres- 


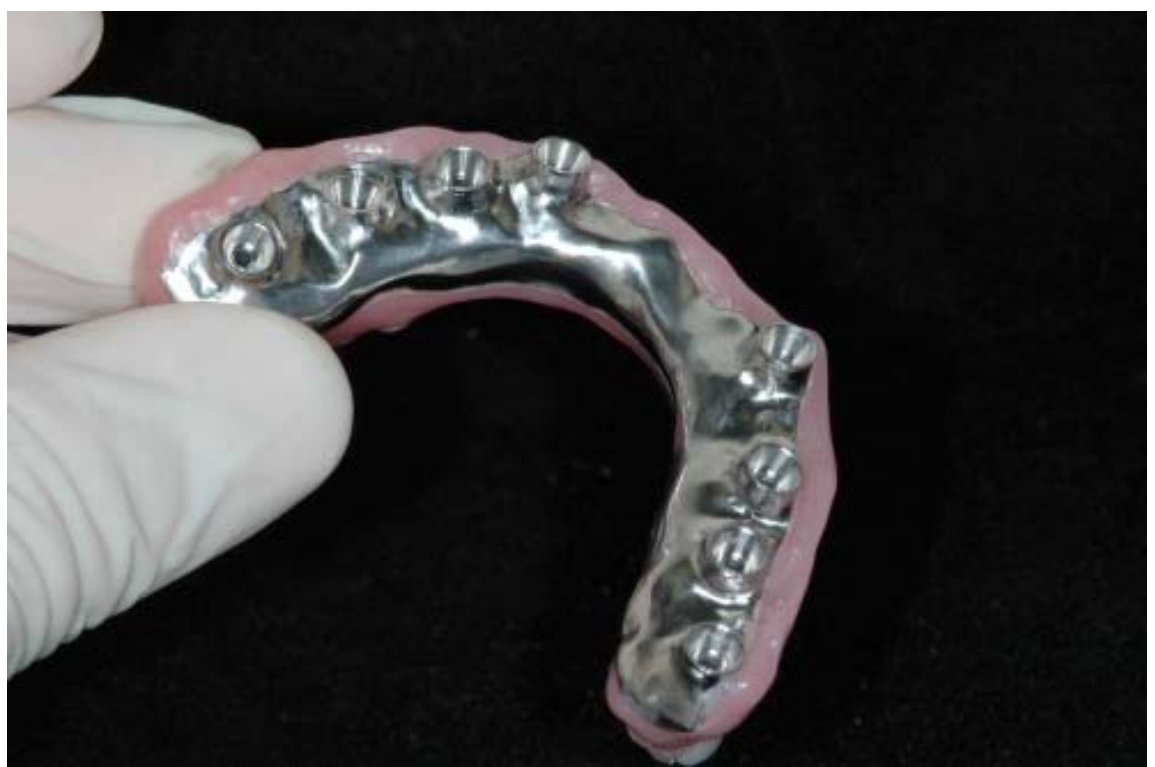

Fig. (4). Intaglio surface of maxillary hybrid has been custom designed in order to improve esthetics and phonetics.

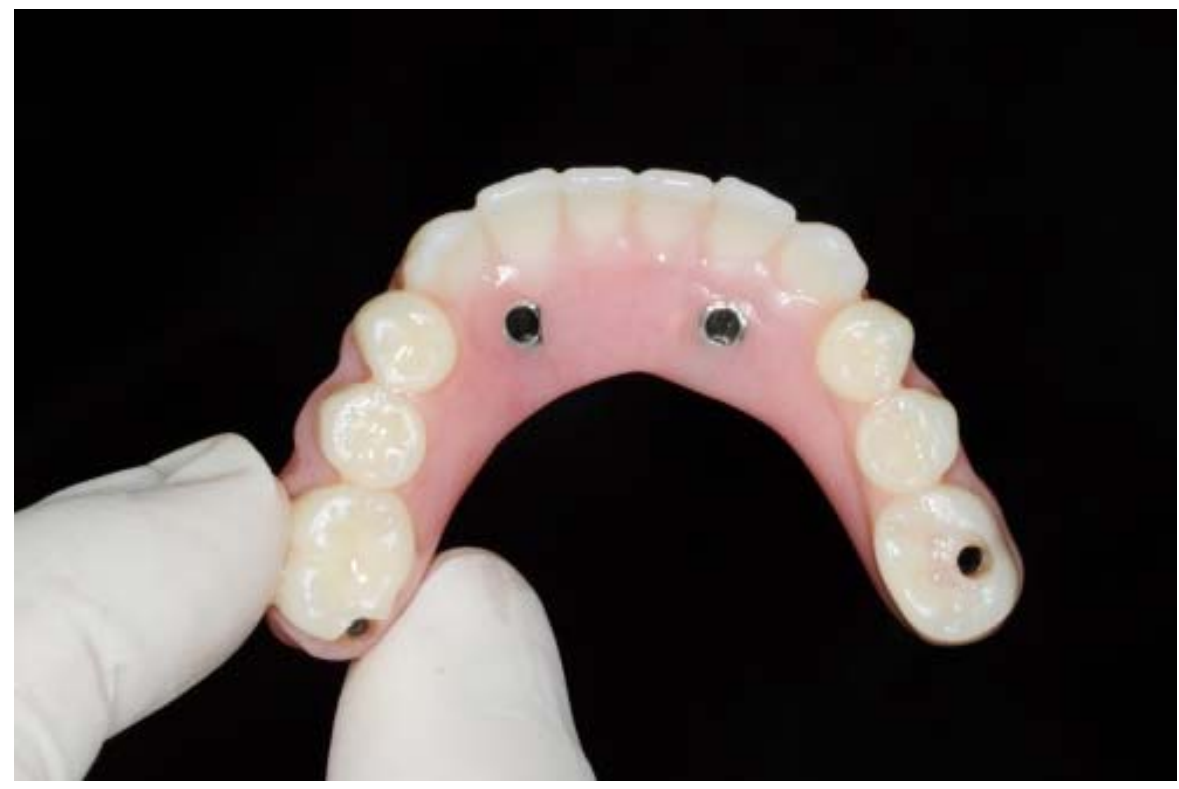

Fig. (5). Ideal implant distribution.

sions, jaw relation records, wax try-in, metal framework tryin, and insertion of definitive prostheses. Frameworks were fabricated according to the following criteria: bulk for strength, adequate access for oral hygiene procedures, minimal display of metal on the facial and occlusal surfaces, and strategic thinning of implant frameworks to allow for retention of acrylic resin denture teeth and denture basses [28].

Traditionally, and according to the original concept of the Brånemark system, implants are placed in a fairly upright position in the anterior edentulous mandible. Therefore, it is often necessary to fabricate a bilateral cantilever, which is sometimes up to $20 \mathrm{~mm}$ long, to provide the patient with good chewing capacity in the molar region. Clinical studies have demonstrated that the distal tilting of implants may be advantageous, with reduction of cantilever length about $6.5 \mathrm{~mm}$ in the mandible and $9.3 \mathrm{~mm}$ in the maxilla $[29,30]$.
The introduction of osseointegration to North America in the early 1980's has created new challenges and opportunities for dental technicians. Totally new concepts of prosthesis design continue to evolve. Structural engineering principles are combined with artistic skills to build an accurately fitting, durable and esthetic prosthesis [31].

Introduced by Malo' et al. in 2003, the All on 4 concept involves the use of 4 implants, including 2 distally tilted ones in areas where bone height; nerve proximity; or the proximity of the sinus, inferior alveolar canal, and/or mental foramen have precluded the placement of axially oriented implants. In addition to preserving the relevant anatomic structures, the distal tilting allows for placement of longer implants with good cortical anchorage in optimal positions for prosthetic support. It also increases the inter-implant spaces, reduces cantilever length, and reduces the need for bone augmentation (Figs. 5 and 6). Published studies on the 


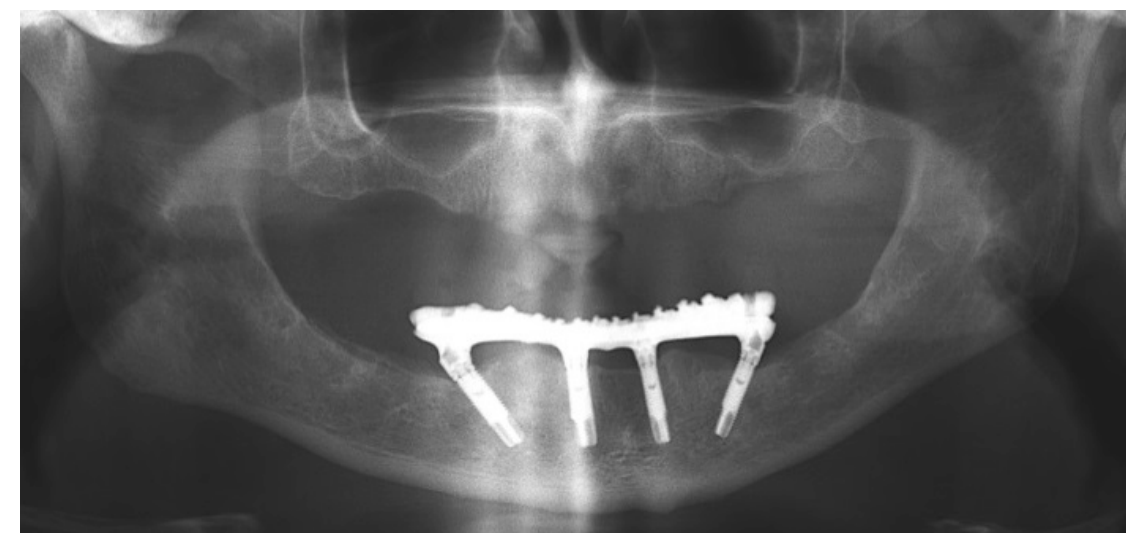

Fig. (6). Prosthetic system out of distal cantilevers.

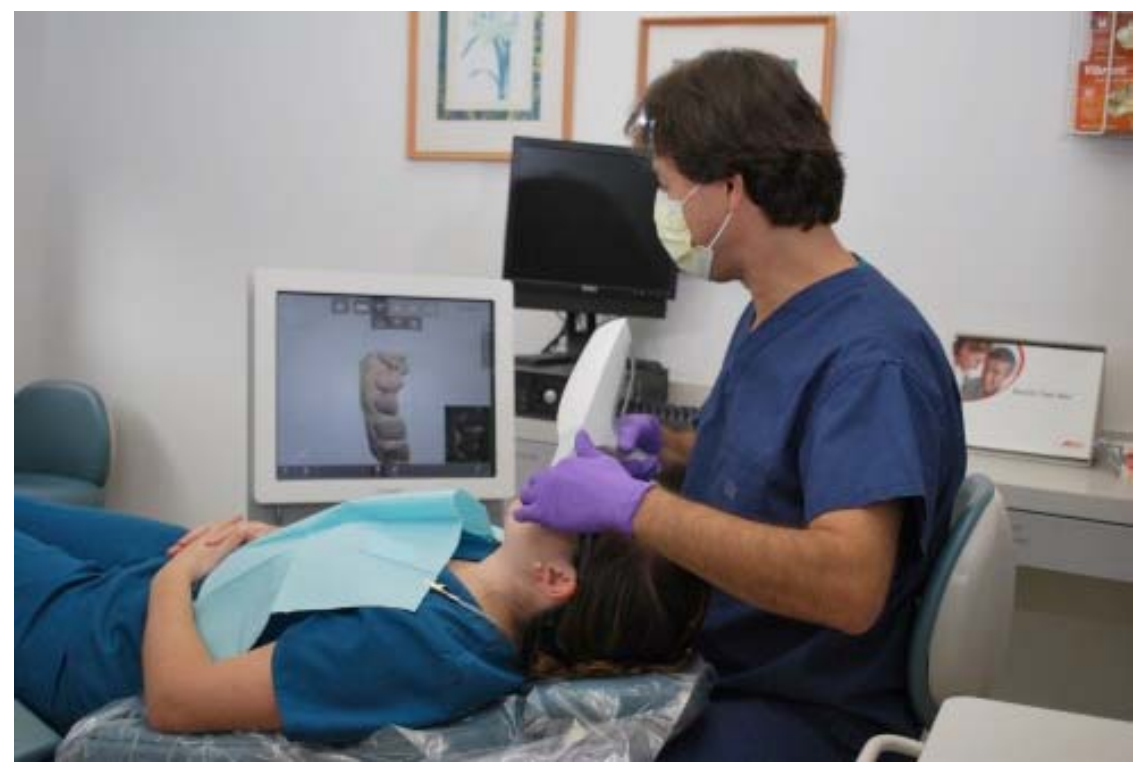

Fig. (7). Intraoral scanner apparatus.

All on 4 concept have shown cumulative survival rates to range between $92.2 \%$ and $100 \%$ [32].

\section{DIGITAL IMPRESSIONS}

A well-accepted principle of restorative dentistry is that the final restoration can be only as accurate and well adapted as the final impression. The clinical challenge is to provide an accurate final impression of the intraoral condition to the laboratory if the impression materials are prone to dimensional changes due to on-going chemical reactions [33] and stone will show expansion due to secondary reactions whilst setting [34]. The misfit of fixed partial dentures on natural teeth will result in forces on the underlying teeth. Natural teeth however can move $25-100 \mu \mathrm{m}$ in axial direction and $56-108 \mu \mathrm{m}$ in lateral direction $[35,36]$ and adapt to a slightly different position in the bone due to the periodontal ligament should there be a slight misfit of the prosthetic work. Implants on the other hand will only show a range of motion of $3-5 \mu \mathrm{m}$ in axial direction and 10-50 $\mu \mathrm{m}$ in lateral direction after osseointegration due to compression of the bone [36]. Ill-fitting frameworks will generate stress on the implants which may have a biological effect on the boneimplant interface [37, 38]. It has been also shown that stresses introduced by misfit were comparable with that related to occlusal forces [39]. Prosthetic complications as screw loosening or fracture may be also related to ill-fitting framework fit [40]. The aforementioned factors have resulted in the paradigm that passive fit of the framework is one of the key factors for long-term success in implant dentistry [41, 42] stressing the importance of a reliable and precise impression procedure. Several strategies have been developed to ascertain passive fit $[35,43]$. An intraoral scanner could overcome some of the errors associated with traditional impression taking [44] and cast production [45], since digital output data can be fed directly into a digital workflow.

In general, all of the current systems follow the basic workflow of computer-assisted design/computer-assisted machining (CAD/CAM) to create a restoration. There are three main sequences to this workflow. The first sequence is to capture or record the intraoral condition to the computer (Fig. 7). This involves the use of a scanner or intraoral camera (Fig. 8). Once the data has been recorded to the computer, a software program (CAD) is used to complete the 


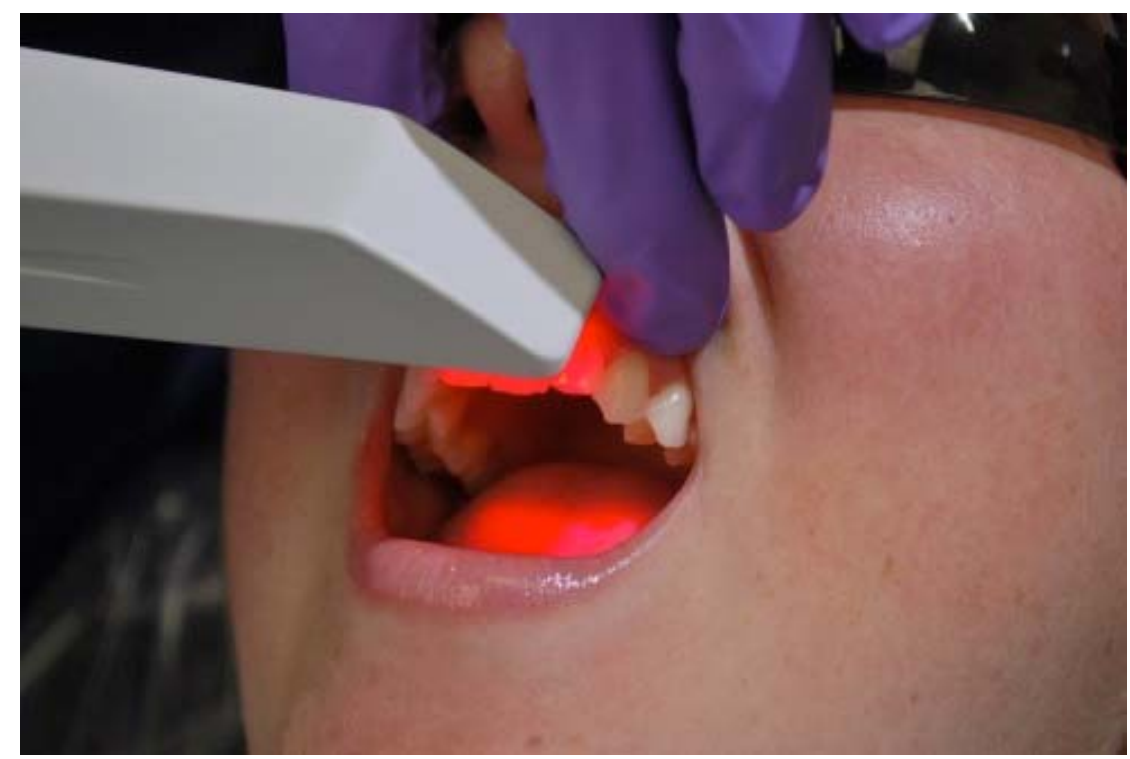

Fig. (8). Intraoral digital impression.

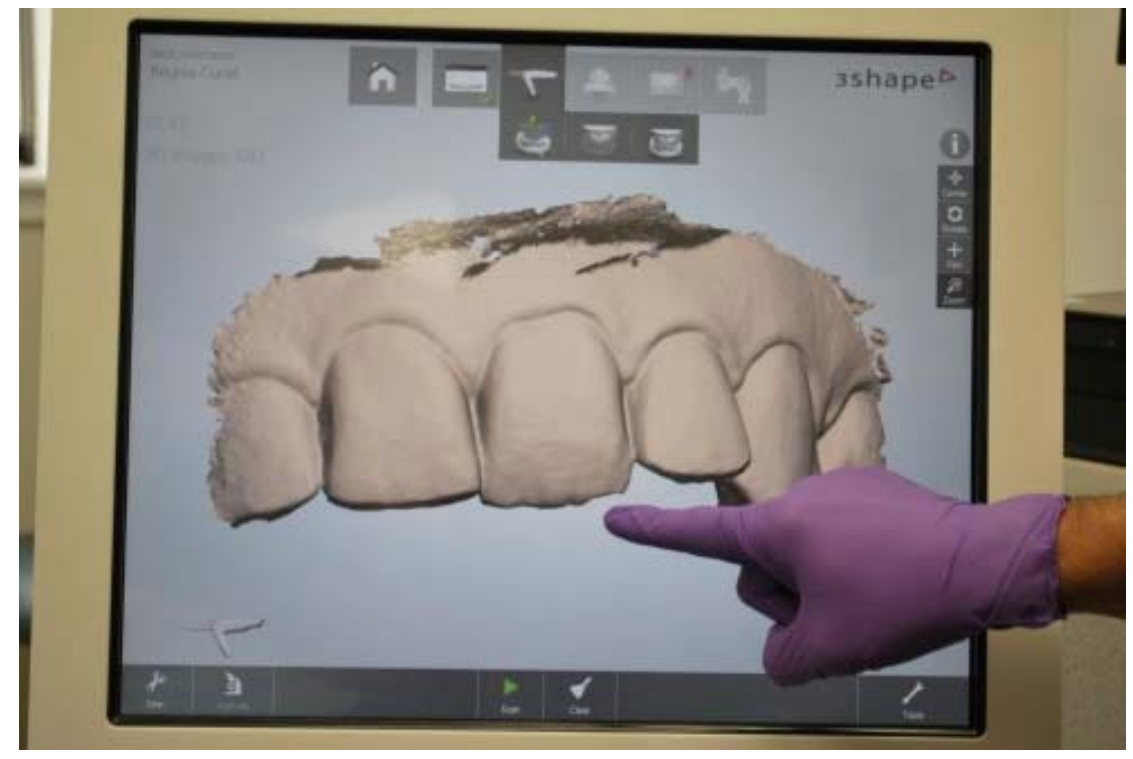

Fig. (9). Design data in the CAD program.

custom design of the desired restoration (Fig. 9). This may involve a full-contour design of the restoration or just the internal coping or substructure of the final restoration. The final sequence requires a milling device to fabricate the actual restoration from the design data in the CAD program (Fig. 10) [46].

\section{ZIRCONIA}

The introduction of computer-aided design/computeraided manufacturing (CAD/CAM) has facilitated the use of new dental ceramic materials. Zirconium oxide, known as zirconia is currently used as a core material for fabrication of frameworks for tooth and implant-supported fixed partial dentures (Fig. 11). Esthetics is optimized with zirconia restorations due to the natural shade of the substrate, thus eliminating the problem of the gray effect, especially at the cervical area, of implant prostheses with metal alloy substructures (Fig. 12) [47]. Zirconia stabilized with yttrium oxide possesses good chemical and physical properties such as low corrosion potential, low thermal conductivity, high flexural strength (900-1200 MPa), and hardness (1200 Vickers) $[48,49]$. In addition, zirconia is considered more biocompatible than other ceramics, titanium, and metal alloys, which may facilitate soft tissue response in terms of heath [50].

However, several authors [51-53] have expressed concern about the long term degradation, or aging, associated with the spontaneous transformation of the metastable tetragonal phase to the monoclinic phase. It has been shown that the spontaneous tetragonal to monoclinic transformation can drastically decrease the mechanical properties of the zirconia by surface roughening, grain pull out, and microcracking [54]. In vivo, these micro-cracks offer a pathway for 


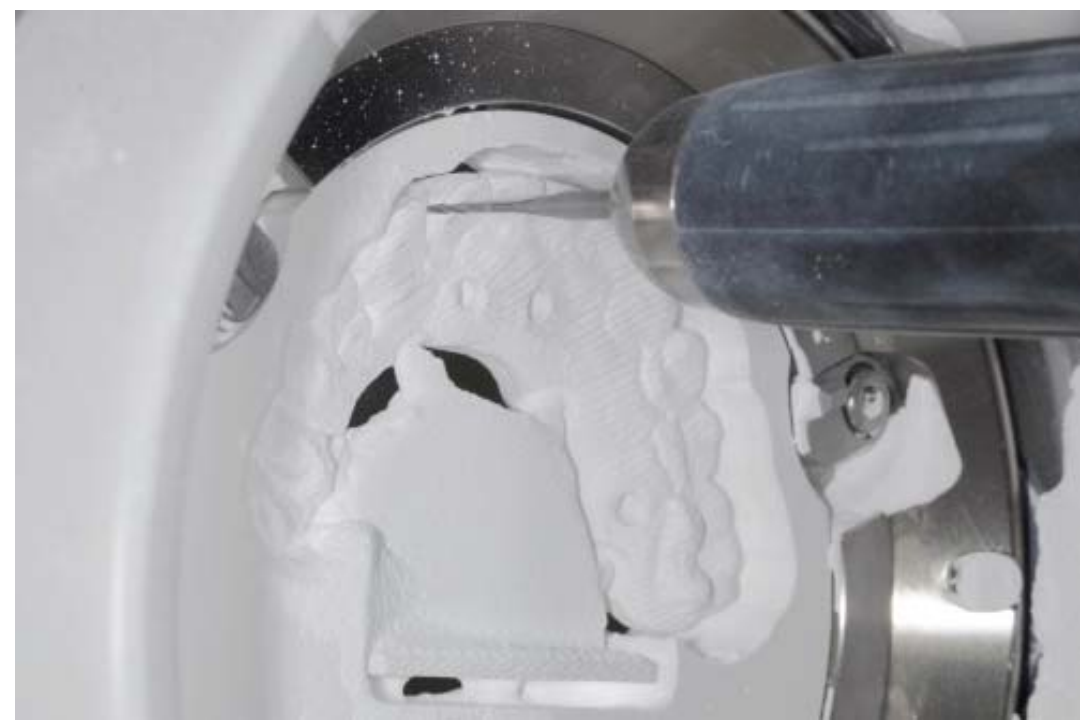

Fig. (10). Milling device.

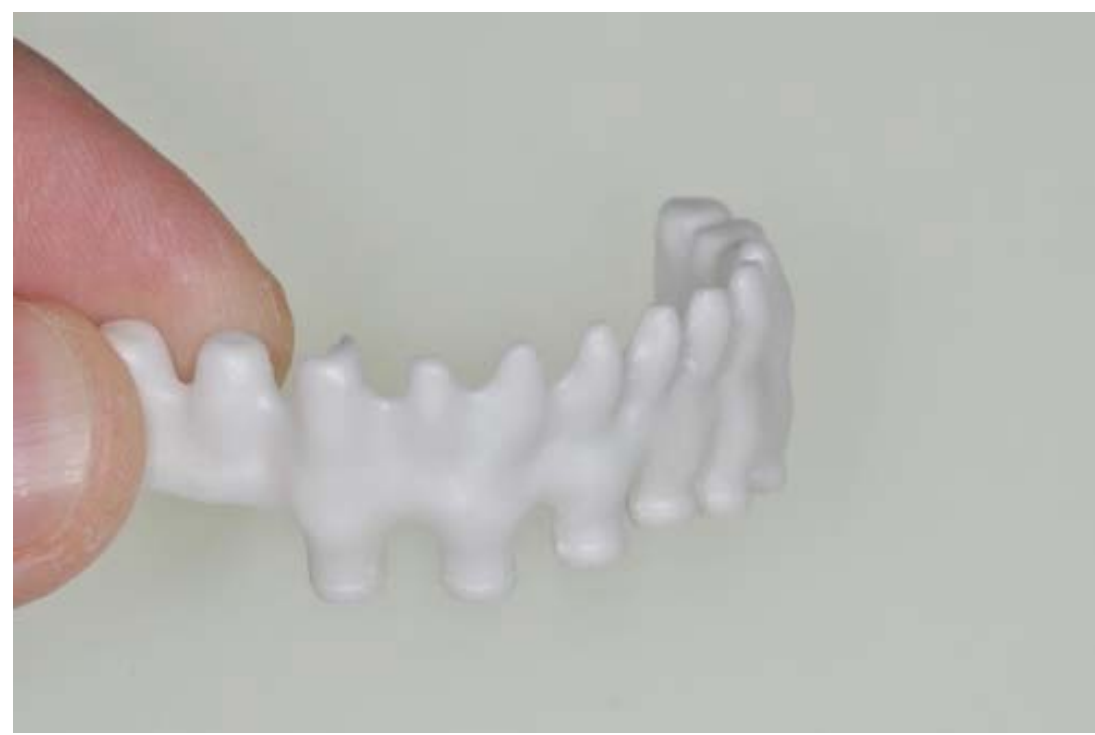

Fig. (11). Zirconia framework for hybrid prosthesis.

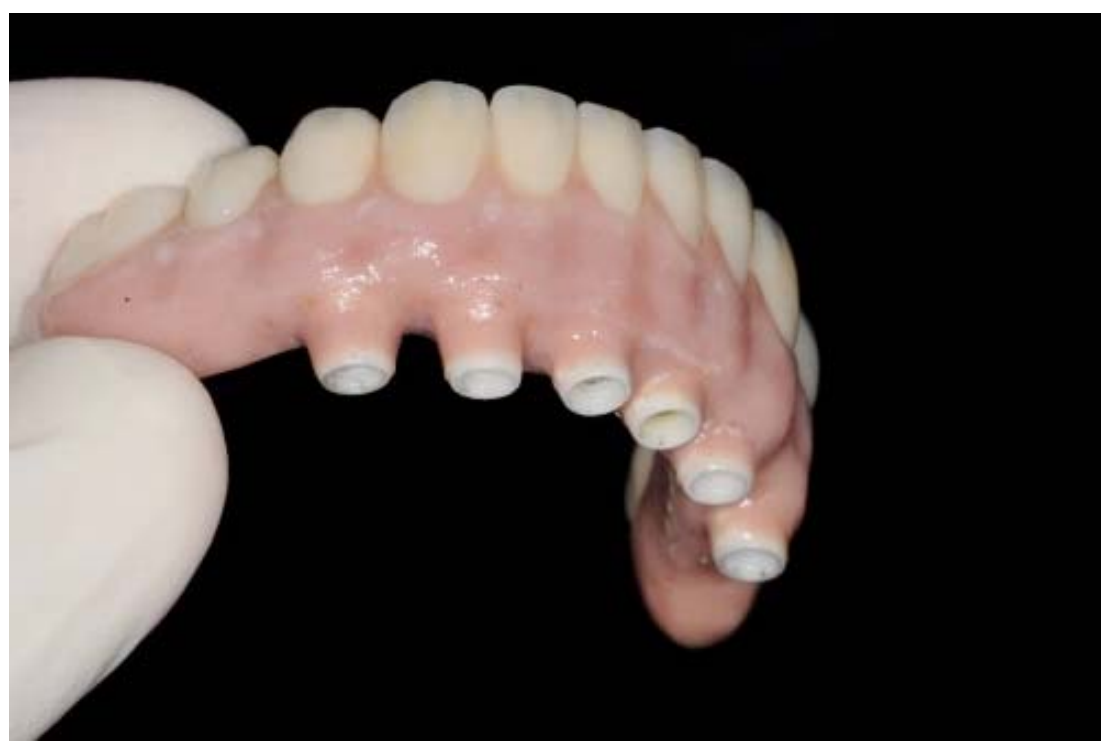

Fig. (12). Hybrid prosthesis with zirconia framework and porcelain veneering material. 


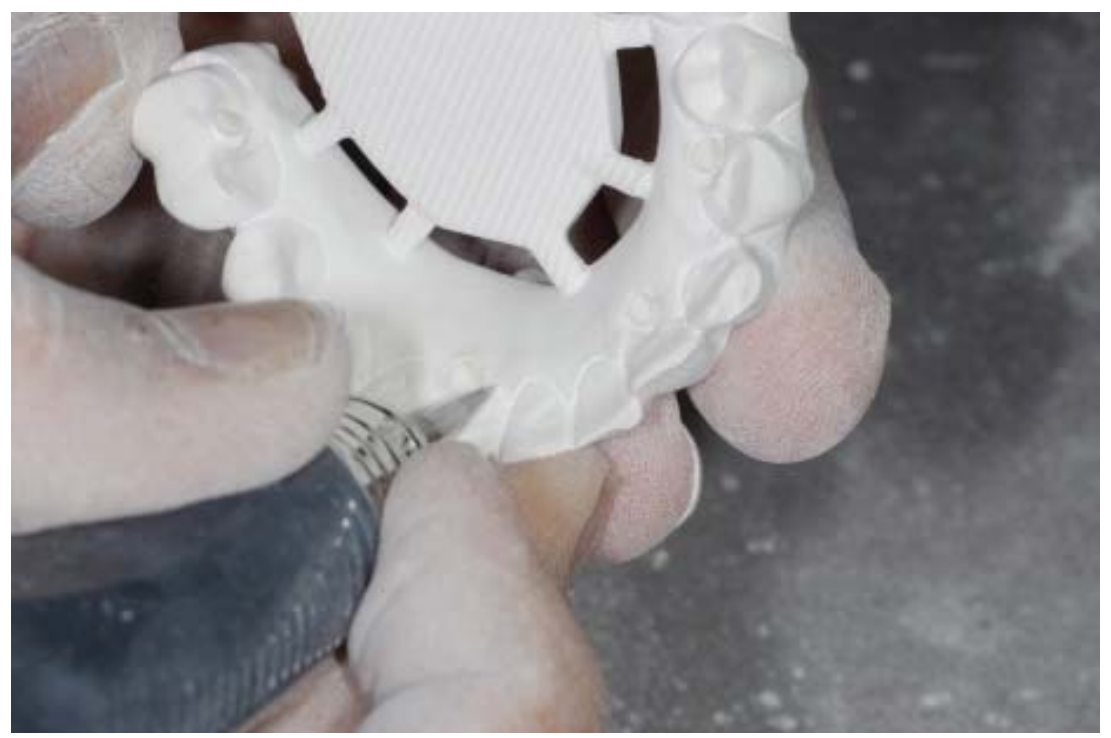

Fig. (13). Monolithic zirconia framework is custom contoured for a partially sintered system.

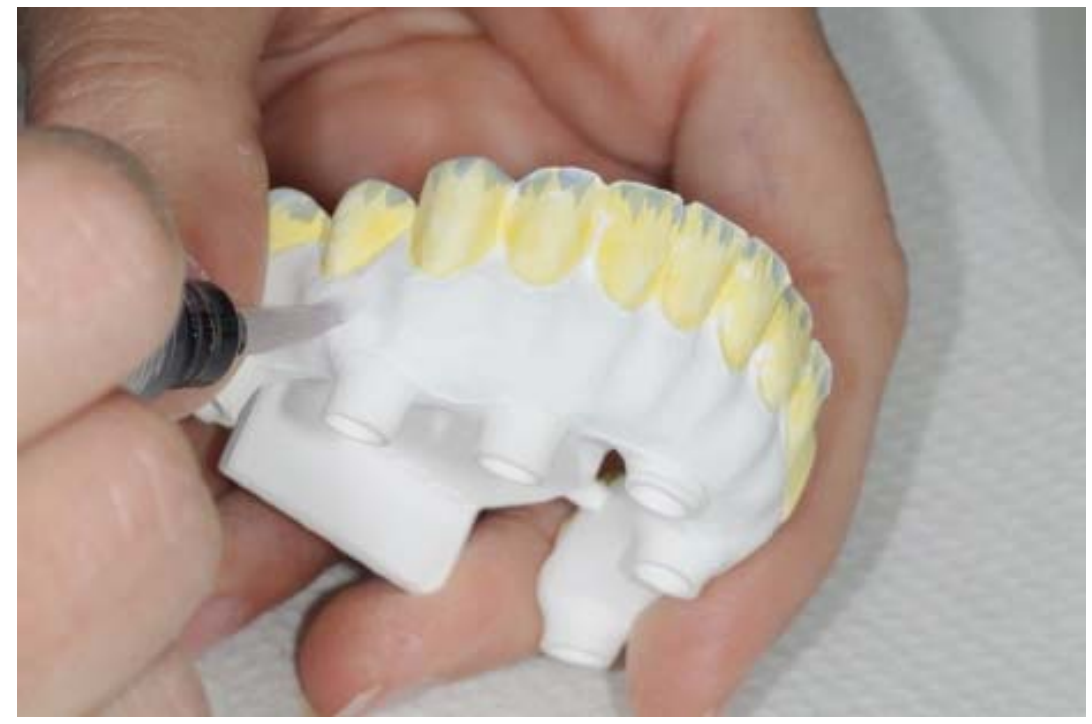

Fig. (14). Monolithic zirconia framework is custom colored for a partially sintered system.

water to diffuse further into the bulk of the ceramic. This transformation occurs when the tetragonal phase is exposed to elevated temperatures, those approaching $250^{\circ} \mathrm{C}$ and/or aqueous environments. It is not well understood how the combination of stresses, temperature, acids, humidity, and saliva in the oral environment affects the rate of this transformation [52]. Several studies have shown that the strength of zirconia test specimens has not been significantly affected by aging according to the ISO standard 13356 (steam autoclave: 5 hours at $0.2 \mathrm{MPa}$ and $134{ }^{\circ} \mathrm{C}$ ) [55]. Molin et al. followed zirconia restorations for at least 5 years concluding that the fracture of zirconia is rare [56-58].

\section{COPY-MILLED ZIRCONIA SYSTEMS}

There is a growing array of digital technology and computerized systems for restorative dental treatment. Most zirconia-based restorative systems use computer-aided design/ computer-aided manufacturing (CAD/CAM) technology for the design and subtractive rapid prototyping technology for the fabrication of the zirconia frameworks. Once the design of the framework is completed, the data is transferred to a milling unit for fabricating the framework. The frameworks can be fabricated from fully sintered zirconium oxide or partially sintered zirconium-oxide blanks. The proponents of partially sintered frameworks claim that micro cracks may be introduced to the framework during the milling procedure of a fully sintered blank, whereas the proponents of milling of a fully sintered blank claim that because no shrinkage is involved in the process the marginal fit is superior $[59,60]$. Probably the partially sintered zirconium technique presents several appealing advantages; the fully customization of framework into monolithic shape (Fig. 13) and intrinsic colorization (Fig. 14). Such ability to control the framework contours and colors provides the ceramist and the clinician additional flexibility, while providing the patient with robust and esthetic restorations (Fig. 15). 


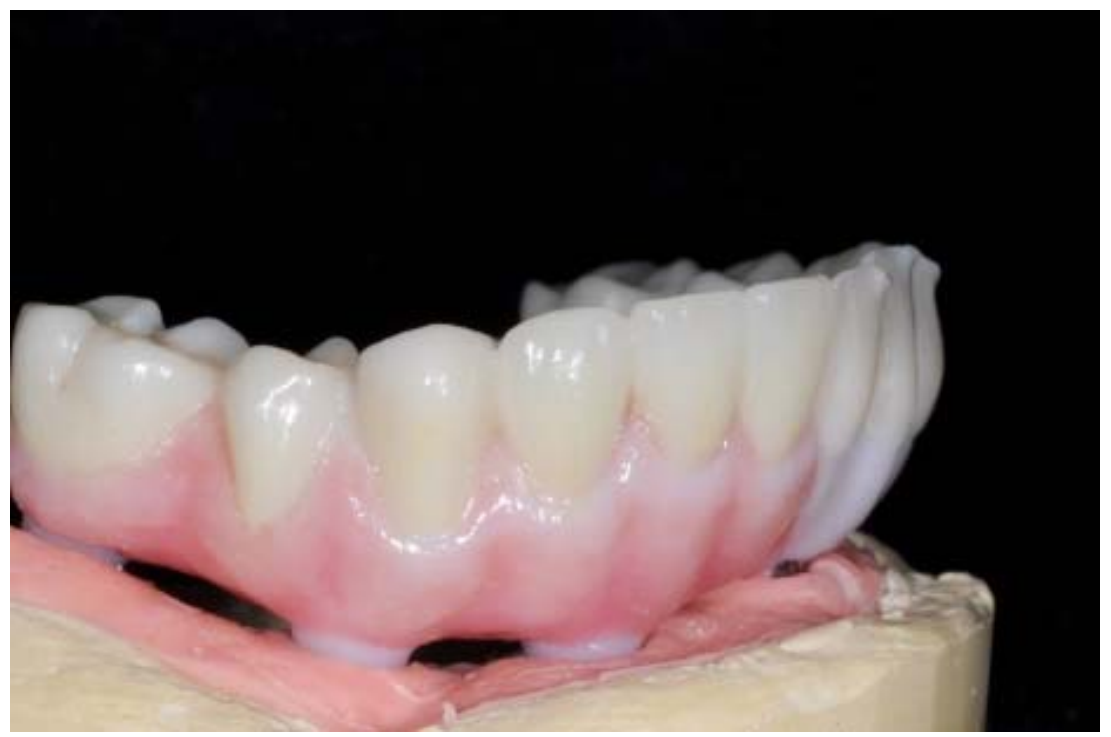

Fig. (15). Special felthpatic porcelain can be added in order to enhance esthetics in specific areas, optional procedure.

\section{CONCLUSION}

This article presented a review of current and past literature regarding the evolution of different materials used for construction of hybrid prostheses. Several advantages can be drawn including CAD/CAM technology, 3D scanning, and monolithic zirconia as framework substrate material. Complications associated with the relative inaccuracy of casting have been significantly improved with the introduction of CAD/CAM technology in implant dentistry. Errors associated with traditional impressions can be solved utilizing 3D scanning since digital output data is fed directly into a digital workflow. Partially sintered monolithic zirconia as an implant-supported prosthetic material, reduces chipping of the veneering porcelain and may requires less prosthetic space compared to a conventional hybrid prosthesis due to its monolithic nature. Improved aesthetics can be achieved due to intrinsic staining capabilities. Such advantages are revolutionizing industries by enabling the merger of mass production and individual customization into fast, cost-efficient workflows that assist in the increasing demand for treatment of the edentulous patient.

\section{CONFLICT OF INTEREST}

The author confirms that this article content has no conflicts of interest.

\section{ACKNOWLEDGEMENTS}

Declared none.

\section{REFERENCES}

[1] Douglass CW, Shih A, Ostry L. Will there be a need for complete dentures in the United States in 2020? J Prosthetic Dent 2002; 87(1): 5-8

[2] Foser H. Philosophie und entwicklung moderener konfektionszahne. Dental Spect 1999; 15: 185-95.
Baker C. History of crown and bridge prosthodontics. In: Tylman SD, Eds. Theory and practice of crown and bridge prosthodontics. St Louis: The CV Mosby Co. 1965.

[4] Johnson W. The history of prosthetic dentistry. J Prosthetic Dent 1959; 9: 841-6.

[5] Ring M. Dentistry, an illustrated history. New York: Abraham HN, Inc 1985; pp. 160-81.

[6] Noort Rv. Introduction to dental materials: health \& fitness. Mosby 1994; p. 236

[7] Jones DW. Development of dental ceramics: an historical perspective. Dent Clin North Am 1985; 29(4): 621-44.

[8] Vivadent I. Scientific documentation IvoBase 2012; p. 3.

[9] Morse DR. Plantation procedures: history, immunology and clinical considerations. J Oral Implantol 1977; 7(2): 176-92 cont'd.

[10] Smollon JF. A review and history of endosseous implant dentistry. Georgetown Dent J 1979; 63(1): 33-45.

[11] Driskell TD. History of implants. CDA J 1987; 15(10):16-25.

[12] Cranin N, Dennison T. Springfield, Ill. New concepts in blade implantology. In: Cranin AN, Ed. Oral Implantology. Charles C Thomas, Publisher; 1970; p. 166

[13] Reade P. Host reactions to tooth transplants. Aust Dent J 1970; 15(3): 172-8.

[14] Ring ME. A thousand years of dental implants: a definitive history: part 1. Compend Contin Educ Dent 1995; 16(10): 1060-4

[15] Association: A.D. ADA survey reveals increase in detal implants over 5 year period (News release on the Internet) 2002; Available from: www.ada.org/public/media/releases/0204_release01.asp

[16] McKinney R. Endosteal dental implants. Mosby Year Book 1991

[17] Zarb GAJT. Prosthodontic procedures. In: Brånemark PI, Zarb G, Albrektsson T, Eds. Tissue-integrated prostheses: osseointegration in clinical dentistry 1985, Chicago: Quintessence Publishing Co., Inc.

[18] Glantz P. Aspects of prosthodontic design. In: Brånermark PI, Zarb G, Albrektsson T, Eds. Tissue-integrated prostheses: osseointegration in clinical dentistry 1985, Chicago: Quintessence Publishing Co., Inc.

[19] Bergman GT. RL, Laboratory technique for the brånemark osseointegrated implant system. Austenal Dental and Northwestern Univerity: Chicago 1987.

[20] Haraldson T. A photoelastic study of some biomechanical factors affecting the anchorage of osseointegrated implants in the jaw. Scand J Plast Reconstr Surg 1980; 14(3): 209-14.

[21] Cox J, Zarb G. Alternative prosthodontic superstructure designs. Swed Dent J Suppl 1985; 28: 71-5.

[22] Brånemark PZ, Albrektsson GA. T, Tissue-integrated prostheses: osseointegration. Clin Dent 1985; Chicago: Quintessence.

[23] Brånemark PI. Biological principles relative to osseointegrated implants. Continuing Education Course, October 1985; Rochester, MN. 
[24] Laurell L. Occlusal forces and chewing ability in dentitions with cross-arch bridges. Swed Dent J Suppl 1985; $26: 160$.

[25] Jemt T, Carlsson L, Boss A, Jörneús L. In vivo load measurements on osseointegrated implants supporting fixed or removable prostheses: a comparative pilot study. Int $\mathrm{J}$ Oral Maxillofac Implants 1991; 6(4): 413-7.

[26] Tallgren A. The continuing reduction of the residual alveolar ridges in complete denture wearers: a mixed-longitudinal study covering 25 years. J Prosthet Dent 1972; 27(2): 120-32.

[27] Atwood DA, Coy WA. Clinical, cephalometric, and densitometric study of reduction of residual ridges. J Prosthet Dent 1971; 26(3): 280-95.

[28] Drago CK. Howell, Concepts for designing and fabricating metal implant frameworks for hybrid implant prostheses. J Prosthodont 2012; 21(5): 413-24.

[29] Malo P, Rangert B, Nobre M. All on 4 immediate-function concept with Branemark System implants for completely edentulous maxillae: a 1-year retrospective clinical study. Clin Implant Dent Relat Res 2005; 7 (Suppl 1): S88-94.

[30] Malo P, Rangert B, Nobre M. "All on 4" immediate-function concept with Branemark System implants for completely edentulous mandibles: a retrospective clinical study. Clin Implant Dent Relat Res 2003; 5 (Suppl 1): 2-9.

[31] Winkelman RO, Kenneth O. Dental implants: fundamental and advanced laboratory technology: Mosby 1994.

[32] Babbush CA, Kanawati A, Brokloff J. A new approach to the All on 4 treatment concept using narrow platform NobelActive implants. J Oral Implantol 2013; 39(3): 314-25.

[33] Johnson GH, Craig RG. Accuracy of four types of rubber impression materials compared with time of pour and a repeat pour of models. J Prosthet Dent 1985; 53(4): 484-90.

[34] Millstein PL. Determining the accuracy of gypsum casts made from type IV dental stone. J Oral Rehabil 1992; 19(3): 239-43.

[35] Sahin S, Cehreli MC. The significance of passive framework fit in implant prosthodontics: current status. Implant Dent 2001; 10(2): 85-92.

[36] Kim Y, Oh TJ, Misch CE, Wang HL. Occlusal considerations in implant therapy: clinical guidelines with biomechanical rationale. Clin Oral Implants Res 2005; 16(1): 26-35.

[37] Sahin S, Cehreli MC, Yalcin E. The influence of functional forces on the biomechanics of implant-supported prostheses: a review. J Dent 2002; 30(7-8): 271-82.

[38] Wang TM, Leu LJ, Wang J, Lin LD. Effects of prosthesis materials and prosthesis splinting on peri-implant bone stress around implants in poor-quality bone: a numeric analysis. Int $\mathrm{J}$ Oral Maxillofac Implants 2002; 17(2): 231-7.

[39] Zarb GA, Schmitt A. Implant prosthodontic treatment options for the edentulous patient. J Oral Rehabil 1995; 22(8): 661-71.

[40] Sones AD. Complications with osseointegrated implants. J Prosthet Dent 1989; 62(5): 581-5.

[41] Branemark PI. Osseointegration and its experimental background. J Prosthet Dent 1983; 50(3): 399-410.

[42] Ongül D, Gökcen-Röhlig B, Sermet B, Keskin H. A comparative analysis of the accuracy of different direct impression techniques for multiple implants. Aust Dent J 2012; 57(2): 184-9.

[43] Abduo J, Bennani V, Waddell N, Lyons K, Swain M. Assessing the fit of implant fixed prostheses: a critical review. Int $\mathrm{J}$ Oral Maxillofac Implants 2010; 25(3): 506-15.
[44] Karl M, Rösch S, Graef F, Taylor TD, Heckmann SM. Strain situation after fixation of three-unit ceramic veneered implant superstructures. Implant Dent 2005; 14(2): 157-65.

[45] Del'Acqua MA, Arioli-Filho JN, Compagnoni MA, Mollo Fde A Jr. Accuracy of impression and pouring techniques for an implantsupported prosthesis. Int J Oral Maxillofac Implants 2008; 23(2): 226-36.

[46] Fasbinder D. Using digital technology to enhance restorative dentistry. Compend Contin Educ Dent 2012; 33(9): p. 666-8, 670, 672 passim.

[47] Sailer I, Holderegger C, Jung RE, et al. Clinical study of the color stability of veneering ceramics for zirconia frameworks. Int J Prosthodont 2007; 20(3): 263-9.

[48] Piconi C, Maccauro G. Zirconia as a ceramic biomaterial. Biomaterials 1999; 20(1): 1-25.

[49] Manicone PF, Rossi Iommetti P, Raffaelli L. An overview of zirconia ceramics: basic properties and clinical applications. J Dent 2007; 35(11): 819-26.

[50] Scarano A, Piattelli M, Caputi S, Favero GA, Piattelli A. Bacterial adhesion on commercially pure titanium and zirconium oxide disks: an in vivo human study. J Periodontol 2004; 75(2): 292-6.

[51] Glauser R, Sailer I, Wohlwend A, Studer S, Schibli M, Schärer P. Experimental zirconia abutments for implant-supported singletooth restorations in esthetically demanding regions: 4-year results of a prospective clinical study. Int J Prosthodont 2004; 17(3): 28590.

[52] Lughi V, Sergo V. Low temperature degradation -aging- of zirconia: a critical review of the relevant aspects in dentistry. Dent Mater 2010; 26(8): 807-20.

[53] Ban S, Sato H, Suehiro Y, Nakanishi H, Nawa M. Biaxial flexure strength and low temperature degradation of Ce-TZP/Al $\mathrm{O}_{2}$ nanocomposite and Y-TZP as dental restoratives. J Biomed Mater Res B Appl Biomater 2008; 87(2): 492-8.

[54] Lilley E. Review of low temperature degradation of tetragonal zirconia ceramics. In: Tressler RE, McNallen H, Ed. Ceramics Transactions, vol. 10, Corrosion and corrosive degradation of ceramics. Westerville, OH: Am Ceramic Soc 1990; pp. 387-406.

[55] International Organization for Standardization. ISO 13356:2008 Implants for surgery -- Ceramic materials based on yttria-stabilized tetragonal zirconia (Y-TZP). Geneva: International Organization for Standardization 2008. Available at:

http://www.iso.ch/iso/en/prods-services/ISOstore/store.html

[56] Molin MK, Karlsson SL. 5 year clinical prospective evaluation of zirconia-based Denzir 3-unit FPDs. Int J Prosthodont 2008; 21(3): 223-7.

[57] Sailer I, Feher A, Filser F, Gauckler LJ, Luthy H, Hammerle CH. 5 year clinical results of zirconia frameworks for posterior fixed partial dentures. Int J Prosthodont 2007; 20(4): 383-8.

[58] Heintze SD, Rousson V. Survival of zirconia- and metal-supported fixed dental prostheses: a systematic review. Int J Prosthodont 2010; 23(6): 493-502.

[59] Luthardt RG, Holzhüter MS, Rudolph H, Herold V, Walter MH. $\mathrm{CAD} / \mathrm{CAM}$-machining effects on Y-TZP zirconia. Dent Mater 2004; 20(7): 655-62.

[60] Suttor D, Bunke K, Hoescheler S, Hauptmann H, Hertlein G. LAVA--the system for all-ceramic $\mathrm{ZrO}_{2}$ crown and bridge frameworks. Int J Comput Dent 2001; 4(3): 195-206.

() Jorge Gonzalez; Licensee Bentham Open.

This is an open access article licensed under the terms of the Creative Commons Attribution Non-Commercial License (http://creativecommons.org/licenses/by-nc/3.0/) which permits unrestricted, non-commercial use, distribution and reproduction in any medium, provided the work is properly cited. 